\title{
Comparison of Different Capacitor Tuning Criteria in Air- Cored Resonant Induction Machines
}

DOI:

10.1109/ECCE.2019.8913143

\section{Document Version}

Accepted author manuscript

Link to publication record in Manchester Research Explorer

\section{Citation for published version (APA):}

lacchetti, M., Jin, Z., Smith, A. C., Deodhar, R., \& Mishima, K. (2019). Comparison of Different Capacitor Tuning Criteria in Air-Cored Resonant Induction Machines. In IEEE https://doi.org/10.1109/ECCE.2019.8913143

\section{Published in:}

IEEE

\section{Citing this paper}

Please note that where the full-text provided on Manchester Research Explorer is the Author Accepted Manuscript or Proof version this may differ from the final Published version. If citing, it is advised that you check and use the publisher's definitive version.

\section{General rights}

Copyright and moral rights for the publications made accessible in the Research Explorer are retained by the authors and/or other copyright owners and it is a condition of accessing publications that users recognise and abide by the legal requirements associated with these rights.

\section{Takedown policy}

If you believe that this document breaches copyright please refer to the University of Manchester's Takedown Procedures [http://man.ac.uk/04Y6Bo] or contact uml.scholarlycommunications@manchester.ac.uk providing relevant details, so we can investigate your claim.

\section{OPEN ACCESS}




\title{
Comparison of Different Capacitor Tuning Criteria in Air-Cored Resonant Induction Machines
}

\author{
Zhao Jin \\ School of Electrical and Electronic Engineering \\ The University of Manchester \\ Manchester, UK \\ zhao.jin-2@postgrad.manchester.ac.uk \\ Alexander C. Smith \\ School of Electrical and Electronic Engineering \\ The University of Manchester \\ Manchester, UK \\ Sandy.Smith@manchester.ac.uk
}

\author{
Matteo F. Iacchetti \\ School of Electrical and Electronic Engineering \\ The University of Manchester \\ Manchester, UK \\ matteo.iacchetti@manchester.ac.uk \\ Rajesh P. Deodhar \\ IMRA Europe SAS UK Research Centre \\ Sussex University \\ Brighton, UK \\ rd@imra-ukrc.com
}

\author{
Keisuke Mishima \\ Powertrain Advanced Development Department \\ Aisin Seiki Co., Ltd. \\ Kariya, Japan \\ k-suke@rd.aisin.co.jp
}

\begin{abstract}
Air-cored Resonant induction machines may offer some interesting features such as reduced inertia and the possibility of operating with square-wave modulation. Their operation is very sensitive to the tuning of the capacitors: by using the equivalent circuit equations this paper analyses different criteria to tune the stator and rotor capacitors. In particular, the paper explores in detail the machine performance in the cases of both stator and rotor capacitors being tuned to resonate with the stator and rotor self-inductances, and stator capacitors only to cancel out the machine input inductance neglecting resistances, and compare these scenarios with two alternative tuning options analysed in a previous paper: both capacitors resonating with the leakage inductances, and stator capacitors tuned to compensate for the overall stator terminal reactance in the absence of rotor capacitors. Analytic expressions for the maximum efficiency and maximum torque and related slip values are also derived as functions of the machine parameters: these expressions provide a valuable tool for design optimisation.

Index Terms-Air Core, Induction Machines, Resonance, Tuning Criteria
\end{abstract}

\section{LIST OF SYMBOLS}

$E_{C s}, E_{C r} \quad$ energy stored in the stator, rotor capacitor (J)

$\overline{I_{s}}, \overline{I_{r}^{\prime}}, I_{s}, I_{r}^{\prime}$ stator, referred rotor current phasor and RMS value (A)

$k$ effective stator to rotor winding turns ratio

$m$

$p_{p}$

$P_{e}$

$P F$

$P_{\text {in }}, P_{\text {out }}$

number of pole pairs

electrical power (W)

power factor

input, output power (W)

$R_{s}, R_{r}^{\prime}$
$R_{t}$
$s, s_{0}, s_{\eta}, s_{T}$
$S$
$T, T_{p k}$
$\overline{V_{s}}, V_{s}$
$X_{C s}, X_{C r}^{\prime}$
$X_{l s}, X_{m}, X_{l r}^{\prime}$
$X_{t}$
$Z_{t}$
$\eta, \eta_{p k}$
$\omega_{s}^{e}$

stator, referred rotor resistance $(\Omega)$ stator terminal resistance $(\Omega)$ slip, prescribed slip, peak efficiency slip, peak torque slip apparent power (VA) torque, peak torque $(\mathrm{Nm})$ stator supply voltage phasor and RMS value $(\mathrm{V})$

stator, referred rotor capacitor reactance $(\Omega)$

stator leakage, magnetising, referred rotor inductance $(\Omega)$

stator terminal reactance $(\Omega)$

stator terminal impedance $(\Omega)$

efficiency, peak efficiency

stator supply frequency $(\mathrm{rad} / \mathrm{s})$

\section{Suffixes}

$\begin{array}{ll}(a),(b),(c),(d) & \text { tuning option }(\mathrm{a}),(\mathrm{b}),(\mathrm{c}),(\mathrm{d}) \\ C & \text { capacitor } \\ g e n . & \text { generating mode } \\ l & \text { leakage } \\ m & \text { magnetising } \\ \text { mot. } & \text { motoring mode } \\ p k & \text { peak } \\ r & \text { rotor } \\ s & \text { stator } \\ T & \text { value related to peak torque } \\ \eta & \text { value related to peak efficiency } \\ l & \text { value referred to the stator side }\end{array}$




\section{INTRODUCTION}

Air-cored resonant induction machines (ACRIMs) have been considered recently for low inertia and high speed applications [1]. The key feature of these machines is the presence of stator and rotor capacitors aimed at partially or totally cancelling out the machine reactances at a given frequency and slip so as to reduce the supply voltage demand for a given torque and speed requirement. The need for capacitors is due to the relatively high leakage inductances of air-cored windings. The basic concept is not new and has been adopted in many applications such as contactless power transmission [2] and resonant converters minimising switching losses [3]. Compared to these well-established systems however, ACRIMs bring the extra complication of variable speed, which makes the tuning of capacitors a trade-off between torque, efficiency and starting capability. So far, the analysis of this type of machines has been based mainly on finite element (FE) simulations, mostly by Sakai, Takijima, Sugasawa [4][7], and only a very few papers have studied the operation analytically in order to highlight the key figures of merit of these machines.

The equivalent circuit incorporating stator and rotor capacitors has been introduced in [6] and validated by FE analysis. The experimental validation was reported in [7], but only for operation at zero speed. In [6], the focus is limited to the operation with stator and rotor capacitors tuned in order to cancel out the stator and rotor self-inductances respectively: no other options are considered and little insight is given into the optimal operating points for torque or efficiency. Reference [8] provides a thorough analysis of the operation with both stator and rotor capacitors - tuned to cancel the stator and rotor leakage inductances respectively, and considers also the more practical option of using stator capacitors only - tuned to achieve resonance, i.e. zero reactance, at the stator terminals Despite this work presenting the key equations for maximum efficiency, torque and related slip values, no comparison is given with the tuning option explored in [7], i.e. with both capacitors tuned to compensate for the self-inductances of the two windings. Furthermore, no key equations for peak torque and efficiency have been derived yet for this scenario.

The relevant expressions for the figures of merit of ACRIMs are derived in this paper, which also presents a thorough comparison among the available tuning options for the capacitors, including the scenarios with no rotor capacitors.

\section{Equivalent Circuit Model AND CAPACitor TUNING OPTIONS}

\section{A. Equivalent Circuit}

Fig. 1 shows the general T-shaped steady-state per-phase equivalent circuit of an ACRIM with capacitors on both stator and rotor, the estimation method for the circuit parameters is given in [8].

\section{B. General Expressions}

Based on this equivalent circuit, the expressions describing the operating characteristics can be derived, among which the

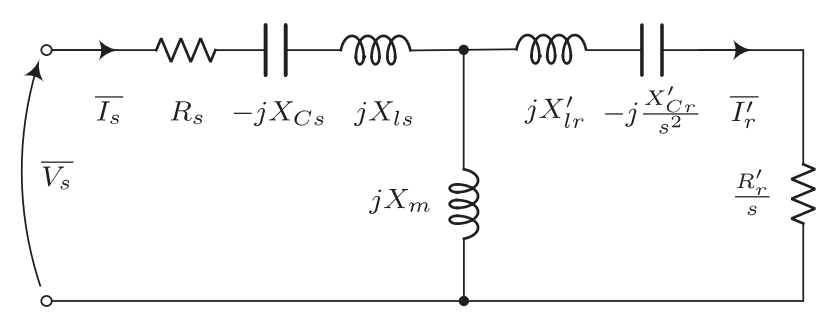

Fig. 1: General T-shaped steady-state per-phase equivalent circuit of an ACRIM (motor convention)

following four groups of terms are found repeatedly, denoted as $G_{1}, G_{2}, G_{3}$ and $D$,

$$
\begin{gathered}
G_{1}=X_{C r}^{\prime}-s^{2}\left(X_{l r}^{\prime}+X_{m}\right) \\
G_{2}=X_{l s}+X_{m}-X_{C s} \\
G_{3}=X_{m}\left(s^{2}\left(X_{l s}-X_{C s}\right)+\left(s^{2} X_{l r}^{\prime}-X_{C r}^{\prime}\right)\right) \\
+\left(X_{l s}-X_{C s}\right)\left(s^{2} X_{l r}^{\prime}-X_{C r}^{\prime}\right) \\
D=s^{2} R_{r}^{\prime} R_{s}\left(2 s X_{m}^{2}+R_{r}^{\prime} R_{s}\right)+G_{3}^{2}+R_{s}^{2} G_{1}^{2}+s^{2} R_{r}^{\prime 2} G_{2}^{2}
\end{gathered}
$$

$G_{1}, G_{2}$ and $G_{3}$ are also associated with the resonant conditions. The equivalent impedance seen from the stator terminals is

$$
\overline{Z_{t}}=R_{t}+j X_{t}
$$

where

$$
\begin{aligned}
& R_{t}=R_{s}+\frac{s^{3} X_{m}^{2} R_{r}^{\prime}}{G_{1}^{2}+s^{2} R_{r}^{\prime 2}} \\
& X_{t}=\frac{s^{2} R_{r}^{\prime 2} G_{2}-G_{1} G_{3}}{G_{1}^{2}+s^{2} R_{r}^{\prime 2}}
\end{aligned}
$$

The torque is calculated using the classical "power balance",

$$
T=\frac{m p_{p}}{\omega_{s}^{e}} I_{r}^{\prime 2} \frac{R_{r}^{\prime}}{s}=\frac{m p_{p}}{\omega_{s}^{e}} \frac{s^{3} X_{m}^{2} R_{r}^{\prime} V_{s}^{2}}{D}
$$

The efficiency for the machine is calculated by taking the ratio of the output power to the input power,

$$
\eta=\frac{P_{\text {out }}}{P_{\text {in }}}=\left(\frac{(1-s) s^{3} R_{r}^{\prime} X_{m}^{2}}{s^{2} R_{r}^{\prime}\left(R_{r}^{\prime} R_{s}+s X_{m}^{2}\right)+R_{s} G_{1}^{2}}\right)^{ \pm 1}
$$

where + and - represent motoring and generating modes respectively, and the efficiency is independent of $X_{l s}$ and $X_{C s}$. The power factor is calculated as the ratio between the electrical power and the apparent power,

$$
P F=\frac{P_{e}}{S}=\frac{\left|R_{s} G_{1}^{2}+s^{2} R_{r}^{\prime}\left(s X_{m}^{2}+R_{r}^{\prime} R_{s}\right)\right|}{\sqrt{D\left(s^{2} R_{r}^{\prime 2}+G_{1}^{2}\right)}}
$$

\section{Capacitor Tuning Options}

Four tuning options are discussed in this paper as listed in Table I.

1) Tuning (a): Stator and rotor capacitors are tuned to compensate for the stator and rotor self-inductances respectively,

$$
\left\{\begin{array}{l}
X_{C s}^{(a)}=X_{m}+X_{l s} \\
X_{C r}^{\prime(a)}=s_{0}^{2}\left(X_{l r}^{\prime}+X_{m}\right)
\end{array}\right.
$$

at prescribed slip $s_{0}$, both $G_{1}$ and $G_{2}$ become zero. 
TABLE I: Capacitor Tuning Options

\begin{tabular}{|c|c|c|c|}
\hline Tuning & $X_{C s}$ & $X_{C r}^{\prime}$ & Comment \\
\hline $\mathrm{a}$ & $X_{m}+X_{l s}$ & $s_{0}^{2}\left(X_{l r}^{\prime}+X_{m}\right)$ & Compensate for the stator and rotor self-inductances. \\
\hline $\mathrm{b}$ & $X_{l s}$ & $s_{0}^{2} X_{l r}^{\prime}$ & $\begin{array}{l}\text { Compensate for the stator and rotor leakage- } \\
\text { inductances. }\end{array}$ \\
\hline $\mathrm{c}$ & $\frac{R_{r}^{\prime 2}\left(X_{l s}+X_{m}\right)+s_{0}^{2}\left(X_{l r}^{\prime}+X_{m}\right)\left[X_{l s} X_{m}+X_{l r}^{\prime}\left(X_{l s}+X_{m}\right)\right]}{R_{r}^{\prime 2}+s_{0}^{2}\left(X_{l r}^{\prime}+X_{m}\right)^{2}}$ & 0 & Compensate for the total terminal reactance. \\
\hline d & $X_{l s}+\frac{X_{m} X_{l r}^{\prime}}{X_{m}+X_{l r}^{\prime}}$ & 0 & $\begin{array}{l}\text { Compensate for the machine input inductance neglect- } \\
\text { ing resistances. }\end{array}$ \\
\hline
\end{tabular}

2) Tuning (b): Stator and rotor capacitors are tuned to compensate for the stator and rotor leakage-inductances respectively,

$$
\left\{\begin{array}{l}
X_{C s}^{(b)}=X_{l s} \\
X_{C r}^{\prime(b)}=s_{0}^{2} X_{l r}^{\prime}
\end{array}\right.
$$

at prescribed slip $s_{0}, G_{3}$ becomes zero.

3) Tuning (c): No rotor capacitor, the stator capacitor is set to cancel out the total equivalent reactance seen from the stator terminals,

$$
\left\{\begin{array}{l}
X_{t}=0 \\
X_{C r}^{\prime(c)}=0
\end{array}\right.
$$

which yields,

$$
\begin{gathered}
X_{C s}^{(c)}=\left\{R_{r}^{\prime 2}\left(X_{l s}+X_{m}\right)+s_{0}^{2}\left(X_{l r}^{\prime}+X_{m}\right)\left[X_{l s} X_{m}+\right.\right. \\
\left.\left.X_{l r}^{\prime}\left(X_{l s}+X_{m}\right)\right]\right\}\left[R_{r}^{\prime 2}+s_{0}^{2}\left(X_{l r}^{\prime}+X_{m}\right)^{2}\right]^{-1}
\end{gathered}
$$

at prescribed slip $s_{0}$, the total equivalent impedance seen from the stator terminals becomes purely resistive which equates to (1).

4) Tuning $(d)$ : No rotor capacitor, the stator capacitor is set to force $G_{3}=0$,

$$
\left\{\begin{array}{l}
G_{3}=0 \\
X_{C r}^{\prime(d)}=0
\end{array}\right.
$$

which yields,

$$
X_{C s}^{(d)}=X_{l s}+\frac{X_{m} X_{l r}^{\prime}}{X_{m}+X_{l r}^{\prime}}
$$

the stator capacitance of tuning (d) is independent of slip, which is different from the rotor capacitances of tuning options (a), (b), and the stator capacitance of tuning (c).

\section{AnALyticAl COMPARISON}

For fixed capacitor values, tuning criteria (a), (b) and (c) can only be fulfilled at a single prescribed slip $s_{0}$. However, assuming variable capacitor values which are adjusted with slip to maintain continuous resonance in the whole slip range helps explore the full potential of these tuning options. In addition, for iron-cored machines, the winding resistances are normally much lower than the leakage reactances, so it is resonable to assume that for air-cored machines whose leakage is more significant, $R_{s}, R_{r}^{\prime}$ are negligible compared with $X_{m}$, $X_{l s}, X_{l r}^{\prime}$, i.e. $R_{s}, R_{r}^{\prime} \ll X_{m}, X_{l s}, X_{l r}^{\prime}$.
The torque and efficiency expressions for each tuning under continuous resonance, $T(s)$ and $\eta(s)$, are derived by substituting the corresponding tuning criteria into the general torque and efficiency expressions, (3) and (4), respectively. The peak torque and peak efficiency points are subsequently solved by analysing the first derivative of $T(s)$ and $\eta(s)$,

$$
\frac{\partial T(s)}{\partial s}=0 \Rightarrow\left(s_{T}, T_{p k}\right), \quad \frac{\partial \eta(s)}{\partial s}=0 \Rightarrow\left(s_{\eta}, \eta_{p k}\right)
$$

the results are summarised in Tables II and III, the peak torque and peak efficiency slips, $s_{T}$ and $s_{\eta}$, the peak torque and peak efficiency, $T_{p k}$ and $\eta_{p k}$, are all functions of the machine parameters.

\section{A. Torque}

To avoid confusion, it needs to be noted that the peak torque in the generating mode refers to the minimum value of $T(s)$ when $s<0$. The critical slip at which the torque tends to infinity should not be selected for $s_{0}$ in practical design [8].

For tuning (a), when $s \rightarrow-R_{r}^{\prime} R_{s} / X_{m}^{2}, T \rightarrow-\infty$, and no stationary point is found under generating mode; in motoring mode, the peak torque is located at a small slip, $s_{T}^{(a)}=$ $R_{r}^{\prime} R_{s} / X_{m}^{2}$.

For tuning (b) and (d), the peak torque points are found in both generating and motoring modes with the peak torque slips

$$
s_{T}^{(b)} \approx \pm \frac{R_{r}^{\prime}}{R_{s}}, \quad\left|s_{T}^{(d)}\right|>\frac{R_{r}^{\prime}}{R_{s}} \frac{1}{\left(1+\frac{X_{l r}^{\prime}}{X_{m}}\right)^{2}}
$$

depending on the resistance and inductance values, $s_{T}^{(b)}$ and $s_{T}^{(d)}$ could be outside the domain of $|s| \leqslant 1$ [8].

For tuning (c), the same peak torque is achieved at two different slips in motoring mode as shown in Table II: the smaller slip with a plus sign in front of the square root, $s_{T, 1}^{(c)}$, and the larger slip with a minus sign, $s_{T, 2}^{(c)}$,

$$
\begin{gathered}
s_{T}^{(a)}=\frac{R_{r}^{\prime} R_{s}}{X_{m}^{2}}<s_{T, 1}^{(c)}<\frac{2 R_{r}^{\prime} R_{s}}{X_{m}^{2}} \ll 1 \\
s_{T, 2}^{(c)}=\sqrt{\frac{R_{r}^{\prime 2} X_{m}^{4}}{4 R_{s}^{2}\left(X_{l r}^{\prime}+X_{m}\right)^{4}}-\frac{R_{r}^{\prime 2}}{\left(X_{l r}^{\prime}+X_{m}\right)^{2}}} \\
+\frac{R_{r}^{\prime} X_{m}^{2}}{2 R_{s}\left(X_{l r}^{\prime}+X_{m}\right)^{2}} \approx \frac{R_{r}^{\prime}}{R_{s}} \frac{1}{\left(1+\frac{X_{l r}^{\prime}}{X_{m}}\right)^{2}}
\end{gathered}
$$


TABLE II: Peak Torque Slip and Peak Torque

\begin{tabular}{|c|c|c|c|}
\hline Tuning & $s_{T}$ & $T_{p k}$ & Comment \\
\hline $\mathrm{a}$ & $\frac{R_{r}^{\prime} R_{s}}{X_{m}^{2}}$ & $\frac{m p_{p} V_{s}^{2}}{\omega_{s}^{e}} \frac{1}{4 R_{s}}$ & $s \rightarrow-s_{T}^{(a)}, T \rightarrow-\infty$ \\
\hline b & $\pm \frac{R_{r}^{\prime}}{R_{s}} \sqrt{1+\frac{R_{s}^{2}}{X_{m}^{2}}}$ & $\frac{m p_{p} V_{s}^{2}}{\omega_{s}^{e}} \frac{1}{2 R_{s}} \frac{1}{1 \pm \sqrt{1+\frac{R_{s}^{2}}{X_{m}^{2}}}}$ & $\begin{array}{l}+ \text { is for motoring mode, }- \text { is } \\
\text { for generating mode. }\end{array}$ \\
\hline $\mathrm{c}$ & $\frac{R_{r}^{\prime} R_{s}}{\frac{X_{m}^{2}}{2} \pm \sqrt{\frac{X_{m}^{4}}{4}-R_{s}^{2}\left(X_{l r}^{\prime}+X_{m}\right)^{2}}}$ & $\frac{m p_{p} V_{s}^{2}}{\omega_{s}^{e}} \frac{1}{4 R_{s}}$ & $s \rightarrow-s_{T}^{(c)}, T \rightarrow-\infty$ \\
\hline $\mathrm{d}$ & $\pm \frac{R_{r}^{\prime}}{R_{s}} \sqrt{\frac{X_{m}^{4}}{\left(X_{l r}^{\prime}+X_{m}\right)^{4}}+\frac{R_{s}^{2}}{\left(X_{l r}^{\prime}+X_{m}\right)^{2}}}$ & $\frac{m p_{p} V_{s}^{2}}{\omega_{s}^{e}} \frac{1}{2 R_{s}} \frac{1}{1 \pm \sqrt{1+\frac{R_{s}^{2}\left(X_{l r}^{\prime}+X_{m}\right)^{2}}{X_{m}^{4}}}}$ & $\begin{array}{l}+ \text { is for motoring mode, }- \text { is } \\
\text { for generating mode. }\end{array}$ \\
\hline
\end{tabular}

TABLE III: Peak Efficiency Slip and Peak Efficiency *

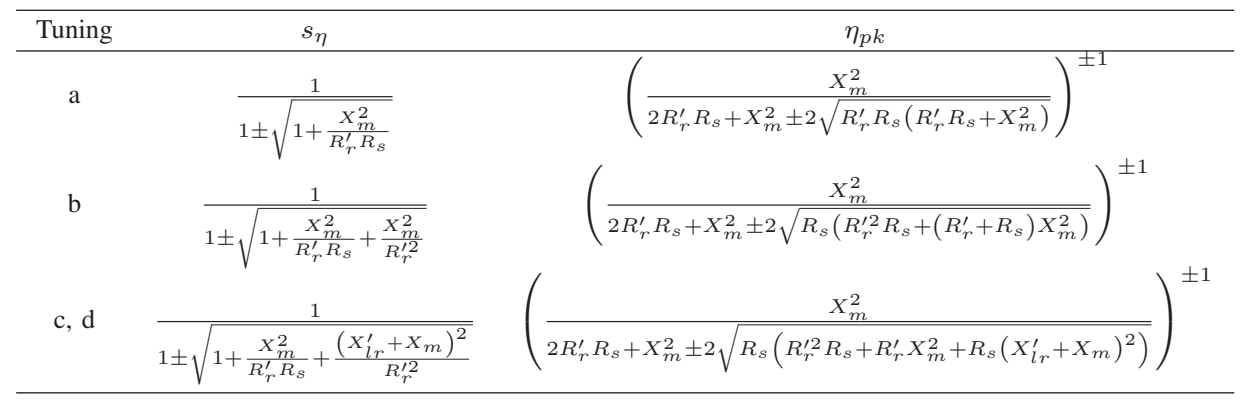

* For all the expressions in this table, + is for motoring mode, - is for generating mode.

$s_{T, 1}^{(c)}$ is small, while $s_{T, 2}^{(c)}$ could be larger than 1 ; In generating mode, when $s \rightarrow-s_{T}^{(c)}, T \rightarrow-\infty$. In addition, There are two other stationary points located at $s= \pm R_{r}^{\prime} /\left(X_{l_{r}}^{\prime}+X_{m}\right)$, but they are turning points rather than peak torque points.

The peak torque listed in Table II are the highest torque possible under different tuning options for the same machine, they can be ranked as follows for the motoring mode,

$$
T_{p k, \text { mot. }}^{(d)}<T_{p k, \text { mot. }}^{(b)}<T_{p k, \text { mot. }}^{(a)}=T_{p k, \text { mot. }}^{(c)}
$$

tuning options (a) and (c) have the same value and the highest torque capability, though they are not considerably larger than options (b) and (d), their location at small slips however may lead to more efficient operation.

\section{B. Efficiency}

As shown in Table III, in terms of the peak efficiency slips, for the same tuning option, $s_{\eta, m o t}<-s_{\eta, g e n}$, i.e. $s_{\eta, m o t}$. is located closer to the synchronous speed than $s_{\eta, g e n}$. Moreover, the distance between $s=0$ and $s_{\eta}$ of the four tuning options under both generating and motoring modes can be ranked as

$$
\left|s_{\eta}^{(c, d)}\right|<\left|s_{\eta}^{(b)}\right|<\left|s_{\eta}^{(a)}\right| \ll 1
$$

so all $s_{\eta}$ are much smaller than 1 , as a result, tuning options (a) and (c) could have the ability to produce high torque at high efficiency because their peak efficiency slips and peak torque slips are close to each other, while options (b) and (d) whose peak torque slips are located further from peak efficiency slips may not be able to attain both high torque and high efficiency simultaneously.

In terms of peak efficiency, under both motoring and generating modes,

$$
\eta_{p k}^{(c, d)}<\eta_{p k}^{(b)}<\eta_{p k}^{(a)}
$$

tuning options (c) and (d) have the same efficiency characteristic because efficiency itself is independent of stator capacitance, and the options with rotor capacitors exhibit the potential to achieve higher efficiency than the options with stator capacitors only.

\section{Power factor}

the terminal reactance and power factor expressions under continuous resonance are derived by substituting the corresponding tuning criteria, into the general terminal reactance and power factor expressions, (2) and (5), respectively.

For tuning options (a) and (c), the power factor remains at " 1 " throughout the whole operating slip range under continuous resonance, which means, for fixed-value capacitors, unity power factor is achieved at the resonance slip $s_{0}$.

For tuning (b), the power factor and terminal reactance expressions under continuous resonance are

$$
P F^{(b)}(s)=\frac{1}{\sqrt{1+\frac{R_{r}^{\prime 4} X_{m}^{2}}{\left(R_{r}^{\prime 2} R_{s}+s\left(R_{r}^{\prime}+s R_{s}\right) X_{m}^{2}\right)^{2}}}}
$$




$$
P F^{(d)}(s)=\frac{\left|\left[R_{r}^{\prime 2} R_{s}+s R_{r}^{\prime} X_{m}^{2}+s^{2} R_{s}\left(X_{l r}^{\prime}+X_{m}\right)^{2}\right]\left(X_{l r}^{\prime}+X_{m}\right)\right|}{\sqrt{\left[R_{r}^{\prime 2}+s^{2}\left(X_{l r}^{\prime}+X_{m}\right)^{2}\right]\left\{\left[s R_{s}\left(X_{l r}^{\prime}+X_{m}\right)^{2}+R_{r}^{\prime} X_{m}^{2}\right]^{2}+\left[R_{r}^{\prime} R_{s}\left(X_{l r}^{\prime}+X_{m}\right)\right]^{2}\right\}}}
$$

$$
X_{t}^{(b)}(s)=\frac{R_{r}^{\prime 2} X_{m}}{R_{r}^{\prime 2}+s^{2} X_{m}^{2}}
$$

When $s=0, P F^{(b)}=1 / \sqrt{1+X_{m}^{2} / R_{s}^{2}} \ll 1$, when $s= \pm 1$, $X_{t}^{(b)} \approx R_{r}^{\prime 2} / X_{m} \approx 0$, as a result, if the prescribed slip $s_{0}$ is close to the synchronous speed, the power factor at $s_{0}$ is low. If $s_{0}$ is close to 1 , the power factor at $s_{0}$ is nearly unity.

For tuning (d), the power factor expression is (11), the terminal reactance expression is

$$
X_{t}^{(d)}(s)=\frac{R_{r}^{\prime 2} X_{m}^{2}}{\left(X_{l r}^{\prime}+X_{m}\right)\left(R_{r}^{\prime 2}+s^{2}\left(X_{l r}^{\prime}+X_{m}\right)^{2}\right)}
$$

when $s=0$,

$$
P F^{(d)}(0)=\frac{1}{\sqrt{1+\frac{X_{m}^{4}}{R_{s}^{2}\left(X_{l r}^{\prime}+X_{m}\right)^{2}}}} \ll 1
$$

so the machine has a low power factor around synchronous speed. However, when $s= \pm 1, X_{t}^{(d)} \approx R_{r}^{\prime 2} X_{m}^{2} /\left(X_{l r}^{\prime}+X_{m}\right)^{3} \approx$ 0 , the equivalent-circuit terminal impedance, $Z_{t}$, is dominated by the resistance, $R_{t}$, therefore the machine has a nearly unity power factor at higher slip.

\section{Capacitance}

The range of stator capacitor reactances under tuning (c) is analysed by differentiating $X_{C s}$ with respect to $s$,

$$
\frac{\partial X_{C s}^{(c)}(s)}{\partial s}=-\frac{2 s R_{r}^{\prime 2} X_{m}^{2}\left(X_{l r}^{\prime}+X_{m}\right)}{\left(R_{r}^{\prime 2}+s^{2}\left(X_{l r}^{\prime}+X_{m}\right)^{2}\right)^{2}}
$$

when $s<0$, $\partial X_{C s}^{(c)} / \partial s>0$; when $s>0, \partial X_{C s}^{(c)} / \partial s<0 ; X_{C s}^{(c)}(s)$ reaches its maximum at $s=0$ and approaches its minimum when $s \rightarrow \infty$,

$$
\begin{aligned}
\lim _{s \rightarrow \pm \infty} X_{C s}^{(c)}(s) & =X_{l s}+\frac{X_{m} X_{l r}^{\prime}}{X_{m}+X_{l r}^{\prime}}=X_{C s}^{(d)} \\
& <X_{C s}^{(c)}( \pm 1)<X_{C s}^{(c)}(s) \\
& \leqslant X_{C s}^{(c)}(0)=X_{m}+X_{l s}=X_{C s}^{(a)}
\end{aligned}
$$

so $X_{C s}$ in tuning (c) is larger than tuning (d), and smaller than tuning (a). Tuning (b) has the smallest $X_{C s}$. The stator capacitances of the four tuning options ranked in the order from the smallest to the largest are

$$
C_{s}^{(a)}<C_{s}^{(c)}<C_{s}^{(d)}<C_{s}^{(b)}
$$

The actual rotor capacitance, $C_{r}=k^{2} C_{r}^{\prime}=k^{2} /\left(\omega_{s}^{e} X_{C r}^{\prime}\right)$, is affected by both the effective stator to rotor winding turns ratio, $k$, and the prescribed slip, $s_{0}$, because $\left|s_{0}\right|$ is less than 1 and usually close to 0 for higher efficiency, $k$ is relatively small compared with $1 / s_{0}^{2}$, as a result, $C_{r}$ can be orders of magnitude larger than $C_{s}$. However, the capacitor size depends on the stored energy rather than the capacitance value: the analytical expressions for the stored energy in stator and rotor capacitors have already been derived in [8].

\section{An ACRIM CASE STUdY}

The quantitative comparisons in this section use a 3-phase, 2-pole, 200V, $250 \mathrm{~Hz}, 171 \mathrm{~kW}$ air-cored machine designd in [8], the equivalent circuit parameters are: $R_{s}=0.0611 \Omega, R_{r}^{\prime}=$ $0.1145 \Omega, X_{l s}=0.5645 \Omega, X_{m}=2.3418 \Omega, X_{l r}^{\prime}=0.5645 \Omega$, $k=1$.

Fig. 2 presents the efficiency versus torque loci, and torque, efficiency, power factor versus slip characteristics for the four different tuning options assuming adjustable capacitor values with slip for options (a), (b) and (c), which in practice, are
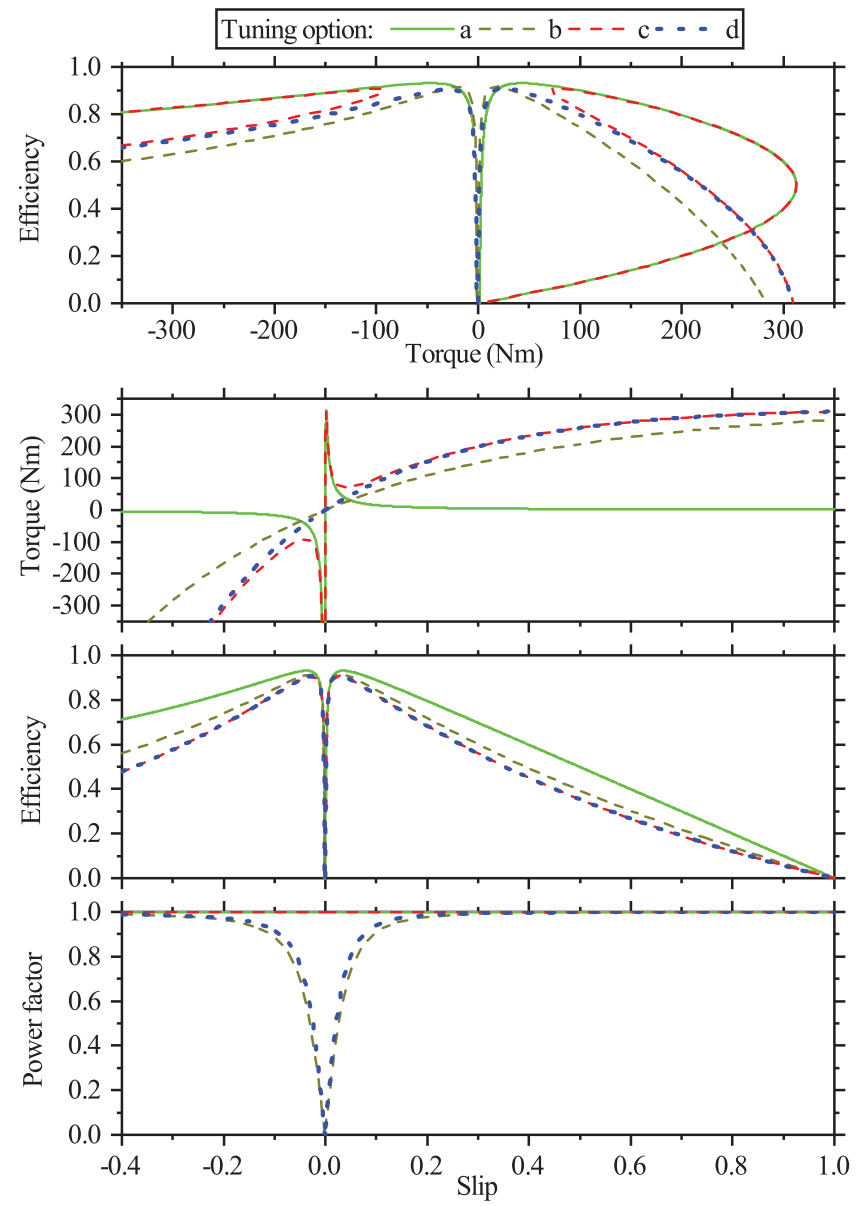

Fig. 2: Efficiency-torque loci, and torque, efficiency, power factor versus slip characteristics for the four tuning options assuming adjustable capacitors with slip for options (a), (b) and (c). 
plotted using the equations of torque and efficiency as functions of slip by varying the slip and simultaneously adjusting the capacitor reactances according to (6), (7) (8) and (9). The efficiency-torque loci of tuning options (a) and (c) overlap over the small slip range in both motoring and generating modes and exhibit the same peak torque capability under motoring mode shown by the nose on the right-hand side of the loci with 0.5 efficiency and $312.6 \mathrm{Nm}$ torque. The efficiencytorque locus of tuning (d) approaches tuning (c) when slip goes higher, but the peak torque for tuning (d), $311.6 \mathrm{Nm}$, is located at a slip of 1.22 which is outside the operating slip range thus can not be observed on the torque-slip curve. A similar situation happens to tuning (b) whose peak torque $312.5 \mathrm{Nm}$ is located at the slip of 1.87 . For the efficiency-slip characteristics, all four tuning options show higher efficiency at lower slip, and the peak efficiencies ranked from the highest to the lowest are $93.11 \%, 91.41 \%, 90.61 \%$ under generating mode and $93.11 \%, 91.65 \%, 90.99 \%$ under motoring mode for options (a), (b), (c,d) respectively. The power factor envelopes of tuning options (b) and (d) decrease quickly when the slip is below 0.2 , which suggests that high power factor can not be maintained at low slip.

In order to have a meaningful comparison of torque and efficiency levels achievable with fixed capacitor values with the different tuning criteria, Fig. 3 presents the efficiencytorque loci, and torque, efficiency, power factor versus slip characteristics under the four different tuning scenarios:

- Tuning (a), with $X_{C s}$ and $X_{C r}^{\prime}$ set with (6) with $s_{0}=$ $s_{\eta, \text { mot }}^{(a)}=0.0345$ determined from Table III for peak motoring-mode efficiency.

- Tuning (b), with $X_{C s}$ and $X_{C r}^{\prime}$ set to compensate for the stator and rotor leakage reactances according to (7) at the peak efficiency slip under motoring mode calculated using Table III, i.e. $s_{0}=s_{\eta, \text { mot. }}^{(b)}=0.0280$.

- Tuning (c), the total terminal reactance is cancelled out by $X_{C s}$ set with (9) at the motoring-mode peak efficiency slip, $s_{0}=s_{\eta, \text { mot. }}^{(c)}=0.0258$ according to Table III, without rotor capacitors.

- Tuning (d), with no rotor capacitors and $X_{C s}$ is set with (10).

As shown in the torque-slip characteristics, tuning options (a) and (c) exhibit similar characteristics though (a) is able to achieve roughly two times higher torque at lower slip so (a) has more overload capability than (c). Conversely, options (b) and (d) are incapable of producing high torque at low slip: in fact the peak torque slips are located at higher slip values outside the plot range and inevitably characterised by lower efficiency as demonstrated in the efficiency-torque loci. For the efficiency-slip curves, the efficiency of tuning (a) is negative over a relatively large slip range under generating mode because of the high magnetising current at low slip, as a result, the input energy is absorbed by the machine itself It should be also noticed that though (a) gives higher peak torque, its efficiency drops quite significantly as soon as the slip is below 0.02. Both tuning options (a) and (c) achieve
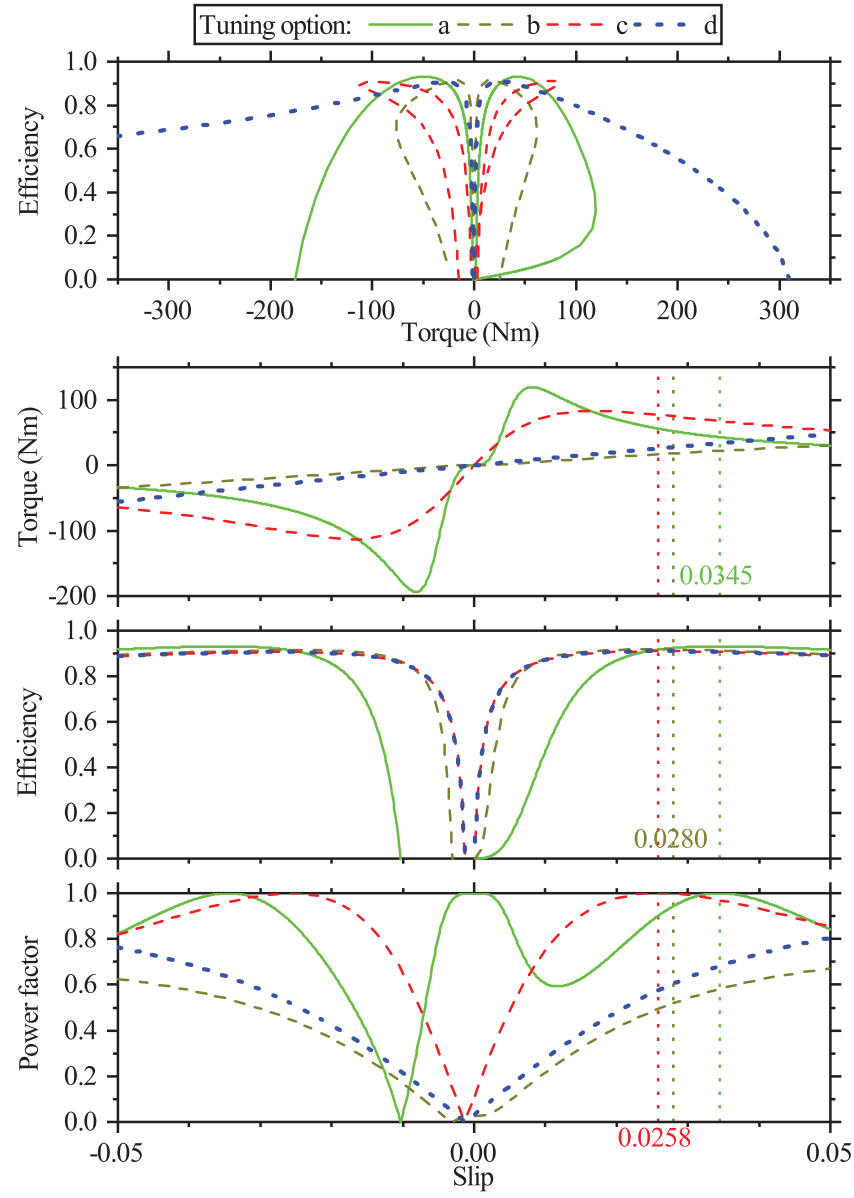

Fig. 3: Efficiency-torque loci, and torque, efficiency, power factor versus slip characteristics for the four tuning options with fixed capacitor values.

unity power factor at their corresponding prescribed slips, 0.0345 and 0.0258 respectively, and maintain a higher power factor than options (b) and (d) around the prescribed slip. In terms of capacitance, the stator capacitances ranked from the largest to the smallest are $1.127 \mathrm{~F}$ for tuning (b), $625 \mu \mathrm{F}$ for tuning (d), $272 \mu \mathrm{F}$ for tuning (c) and $219 \mu \mathrm{F}$ for tuning (a), the rotor capacitances are $1.436 \mathrm{~F}$ for tuning (b) and $184 \mathrm{mF}$ for tuning (a), the rotor capacitances are about $10^{3}$ larger than the stator capacitances for the same tuning, and tuning (b) has the highest capacitance requirement.

The efficiency-torque loci in Fig. 2 also reveals that tuning options (a) and (c) have similar torque and efficiency capability at small slip values, which suggests it should be possible to change the reference slip value of tuning (c) in (9) to move away from the maximum efficiency slip, $s_{\eta}^{(c)}=0.0258$ for this machine, to a smaller slip so as to boost the peak torque but at the expense of peak efficiency. This should result in a torque-slip characteristic closer to that of tuning (a) in Fig. 3.

Fig. 4 compares the efficiency-torque loci, and torque, efficiency, power factor, stator current versus slip charac- 

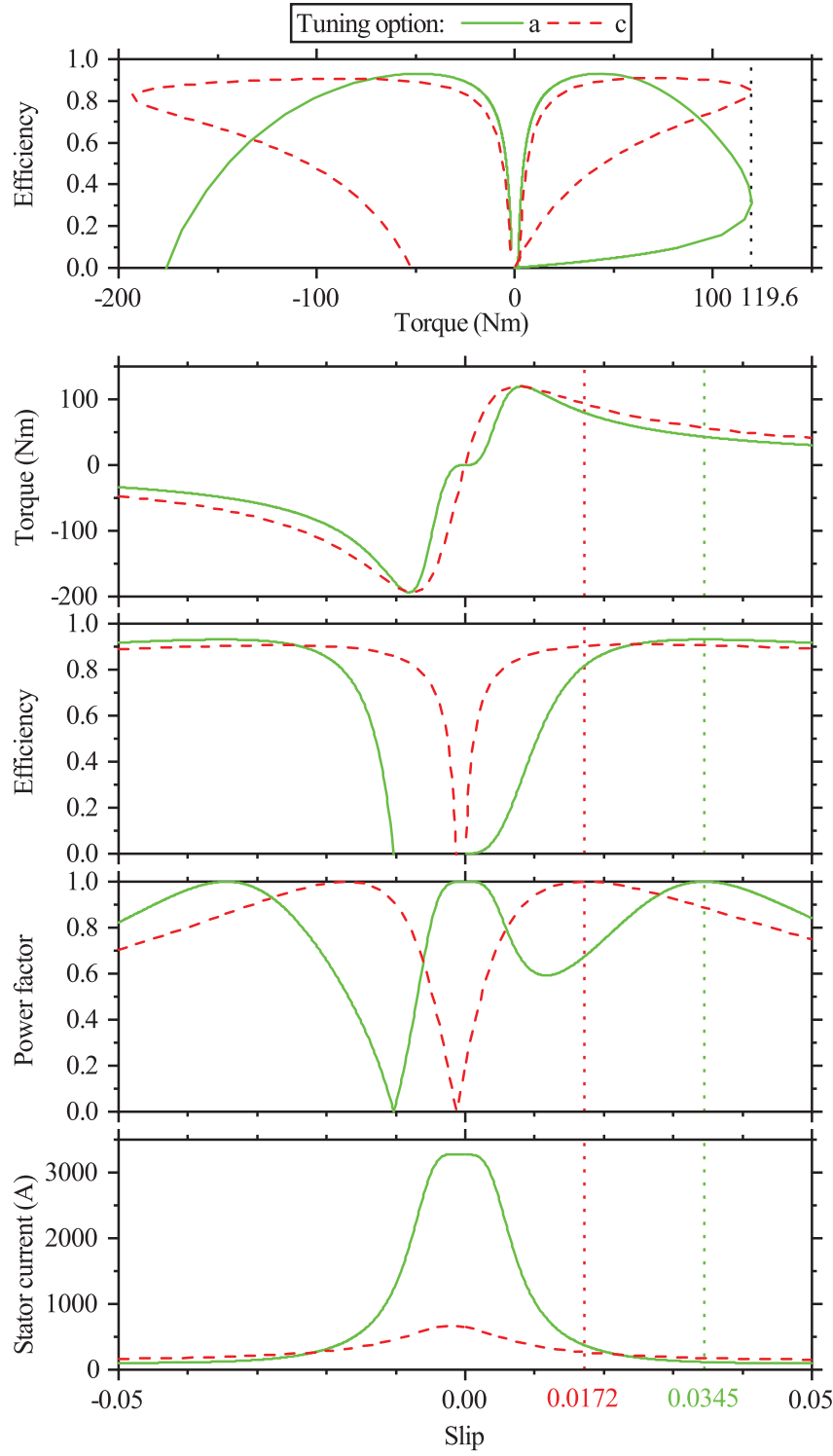

Fig. 4: Efficiency-torque loci, and torque, efficiency, power factor, stator current versus slip characteristics for the tuning (a) and modified tuning (c) with fixed capacitor values.

teristics for tuning (a) under peak efficiency scenario with $s_{0}=s_{\eta, \text { mot. }}^{(a)}=0.0345$ in (6), and tuning (c) with modified reference slip $s_{0}=0.0172$ in (9) in order to achieve the same peak torque. This modified tuning (c) still described by (8) achieves a torque-slip characteristic very similar to (a), with the same motoring-mode peak torque, $119.6 \mathrm{Nm}$. Although the peak efficiency in (c), $\eta_{p k, \text { mot. }}^{(c)}=91 \%$ is lower than (a), $\eta_{p k, \text { mot. }}^{(a)}=93 \%$, the efficiency for peak torque under tuning (c) is larger than tuning (a). The trend of efficiency versus torque becomes flatter as shown in the locus compared with the previous tuning (c), which means the high efficiency can be maintained over a wider range of torque. In terms of power factor, tuning (c) stays above 0.8 around both the reference slip and peak torque slip, while the power factor of tuning (a) drops to 0.6 around the peak torque slip. Furthermore, The stator current characteristics reveal that tuning (a) suffers from a severe stator overcurrent when the slip approaches zero, because the stator capacitor cancels out the stator self-inductance and the stator current is then only limited by the small value of the stator resistance. Tuning (c) does not suffer from this drawback. The stator capacitance calculated for the modified tuning (c) is $244 \mu \mathrm{F}$ which is smaller than the previous tuning, but is still larger

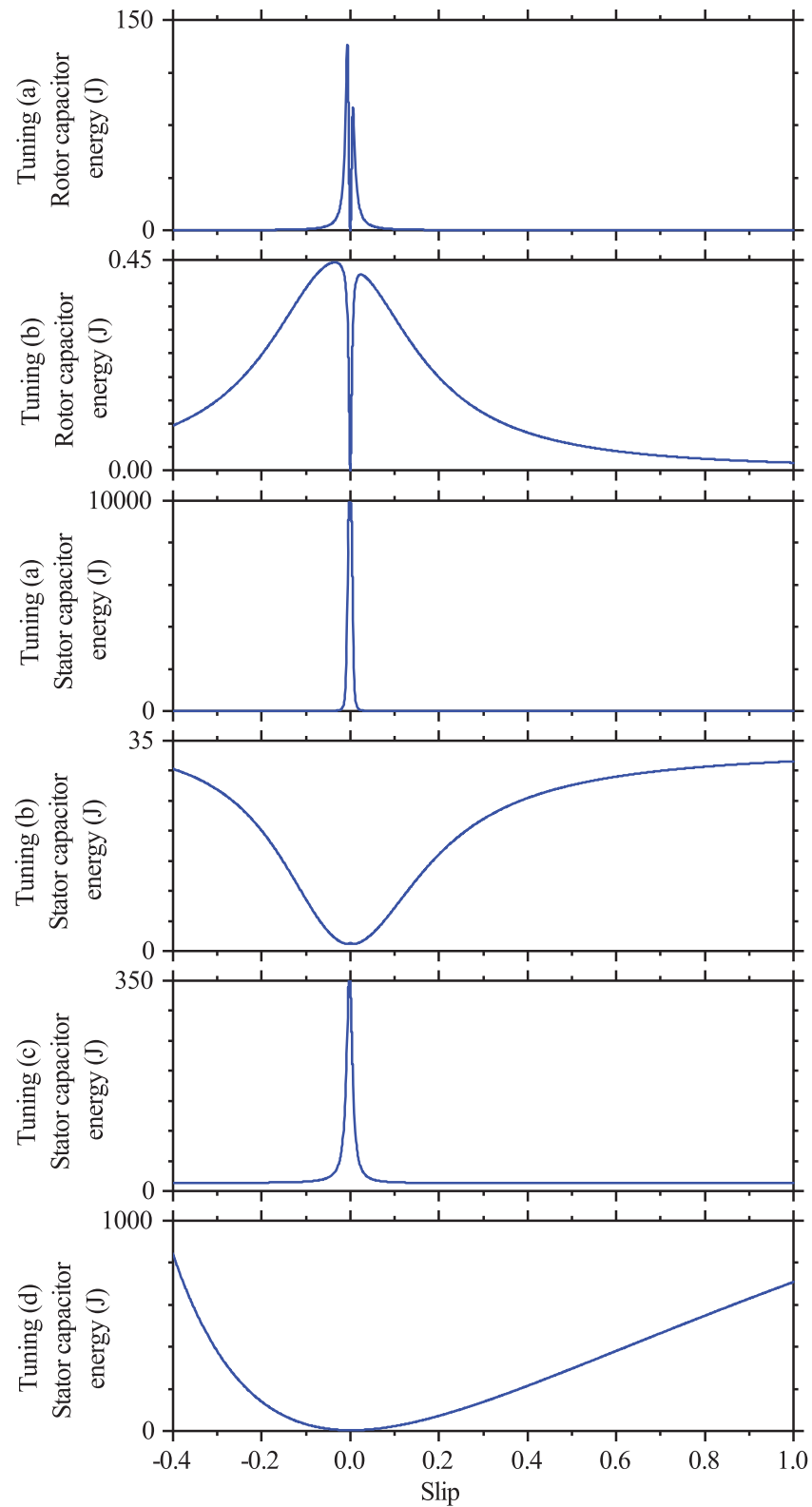

Fig. 5: Energy stored in stator and rotor capacitors versus slip characteristics for the original tuning options (a), (b), (d) and modified tuning (c) with fixed capacitor values. 
than tuning (a). However, the capacitor selection should also consider the worst case scenario: depending on the slip, apart from the larger rotor capacitance, the overcurrent under tuning (a) around synchronous speed leads to a higher rated stator capacitor.

Fig. 5 shows the energy stored in the stator and rotor capacitors for the original tuning options (a), (b), (d) and the modified tuning (c). The peak values of the capacitor-stored energy within the operating slip range $-0.4<s<1$ are ranked from the highest to the lowest as $E_{C s, p k}^{(a)}>E_{C s, p k}^{(d)}>$ $E_{C s, p k}^{(c)}>E_{C r, p k}^{(a)}>E_{C s, p k}^{(b)}>E_{C r, p k}^{(b)}$. It can be seen that more energy is stored in the stator capacitors than the rotor capacitors for the same tuning method, and tuning (b) has the lowest stored energy level but the largest capacitance value so the lowest voltage rating as well. The highest $E_{C s, p k}^{(a)}$ indicates that the capacitor size for tuning (a) is bigger than tuning (c), and is the largest among the four tuning options within the given operating slip range.

\section{CONCLUSION}

This paper analyses four different tuning options for the capacitors in air-cored resonant induction machines. The study reveals that tuning the stator and rotor capacitors in order to resonate with the stator and rotor self-inductances respectively, i.e. tuning (a), gives the best efficiency and a high torque capability. However, similar figures can be achieved by removing the rotor capacitors and tuning the stator capacitors to compensate for the total equivalent reactance seen from the stator terminals, i.e. tuning (c). This solution does not suffer from overcurrent at zero slip and has the advantage of eliminating the rotor capacitors which may be difficult to fit in a high speed rotor. Compact analytical expressions for the maximum torque and maximum efficiency and related slip values are also presented to ease the optimisation procedure for designing ACRIMs.

\section{REFERENCES}

[1] K. Sakai and Y. Sugasawa, "Ultralightweight motor design using electromagnetic resonance coupling," 2016 IEEE Energy Conversion Congress and Exposition (ECCE), Milwaukee, WI, 2016, pp. 1-7.

[2] D. A. G. Pedder, A. D. Brown and J. A. Skinner, "A contactless electrical energy transmission system," in IEEE Transactions on Industrial Electronics, vol. 46, no. 1, pp. 23-30, Feb 1999

[3] J. Hou, Q. Chen, S. C. Wong, C. K. Tse and X. Ruan, "Analysis and Control of Series/Series-Parallel Compensated Resonant Converter for Contactless Power Transfer," in IEEE Journal of Emerging and Selected Topics in Power Electronics, vol. 3, no. 1, pp. 124-136, March 2015.

[4] Y. Sugasawa, K. Sakai, "Basic study on electromagnetic resonance motor," Proc. 2015 IEEJ Industry Application Society.

[5] K. Sakai and K. Takijima, "Basic Characteristics of an Ultra-Lightweight Magnetic Resonance Coupling Motor with Various Numbers of Poles," 2018 IEEE Energy Conversion Congress and Exposition (ECCE), Portland, OR, 2018, pp. 7342-7348.

[6] K. Takishima and K. Sakai, "Equivalent Circuit Analysis of an UltraLightweight Motor Designed with Magnetic Resonance Coupling,” 2018 20th European Conference on Power Electronics and Applications (EPE'18 ECCE Europe), Riga, 2018, pp. P.1-P.9.

[7] K. Takishima and K. Sakai, "Analytical and Experimental Investigation of the Frequency Characteristics of an Ultra-Lightweight Motor Based on Magnetic-Resonance Coupling," 2018 XIII International Conference on Electrical Machines (ICEM), Alexandroupoli, 2018, pp. 562-568
[8] M. F. Iacchetti, A. C. Smith, R. P. Deodhar and K. Mishima, "Modelling and Operating Characteristics of Air-Cored Resonant Induction Machines," 2018 IEEE Energy Conversion Congress and Exposition (ECCE), Portland, OR, 2018, pp. 6468-6475. 